\title{
James Israel: \\ Meine Reise zum Sultan (1915)
}

Bemerkungen zum Tagebuch einer ärztlichen Mission

von Werner Sackmann

\section{Der ärztliche Autor und sein Tagebuch}

Das Leben und Werk von James Israel (1848-1926) ist im medizingeschichtlichen Schrifttum wiederholt gewürdigt worden, bis in unsere Tage [1]. Als einer der angesehensten Chirurgen seiner Zeit ist er der Nachwelt in Erinnerung geblieben, nicht nur als mutiger Pionier in fachberuflicher Hinsicht, sondern auch allgemein als begnadeter Lehrer von Generationen von Schülern und als hingebungsvoller Betreuer einer zahlreichen Klientele aller Stände und Nationen. Seine Sorge galt ebenso den ärmsten Ostflüchtlingen, die zu ihm nach Berlin pilgerten [2], wie den Spitzen der Gesellschaft, den Regierenden und Fürstenhöfen, die der Weitgereiste bisweilen zu beraten und zu versorgen hatte.

Seine eindrücklichste ärztliche Mission war - nach Israels eigenem Urteil diejenige, welche ihn 1915 nach Konstantinopel (Istanbul) führte, den Herrscher des Osmanischen Reiches, Sultan Mohammed V., zu operieren. Daß Israel über jene Reiseerlebnisse eigens Tagebuch geführt hatte, ist schon im Nachruf von Kraus erwähnt [3]; doch verblieb das maschinengeschriebene Dokument ausschließlich in Privatbesitz, und zwar m. W. in zwei Exemplaren. Eines befindet sich heute in Händen des Enkels Peter Bloch in New York; das andere hat der kinderlose Sohn Arthur Israel (1883-1969) seinem Freunde Prof. Rudolf Nissen (1897-1981) in Basel anvertraut ${ }^{1}$.

Dieses Tagebuch, das eine eigenständige Herausgabe durchaus verdient hätte, ist zwar kürzlich von $P$. Bloch veröffentlicht worden, allerdings in unauffälliger und gänzlich unkommentierter Form als Teil einer umfangreichen Israel-Biographie [4]. Der dort nachzulesende, nahezu vollständige Text diente als Grundlage zu dem vorliegenden Versuch, Inhalt und Verlauf der Episode in großen Zügen nachzuvollziehen und in einen zeitgeschichtlichen Rahmen zu stellen, sowie ergänzende Informationen zu geben. Der chronologische Ablauf wurde dabei nach Möglichkeit aufgezeigt, war jedoch nicht allein maßgebend für die Gliederung des Stoffes. 


\section{Der kaiserliche Patient und sein Reich}

Die osmanischen Herrscher des 19. Jahrhunderts hatten sehr wohl die Überlegenheit der modernen, abendländischen Welt erkannt. Sie versuchten auf vielerlei Weise, Anschluß an dieselbe zu gewinnen und ihren eigenen zivilisatorischen Rückstand aufzuholen. Infolgedessen war ihr Reich, das bis zum Ersten Weltkrieg außer der heutigen Türkei noch die Gebiete des Irak und des Libanon, die Westküste Arabiens sowie Syrien, Jordanien und Palästina umfaßte, gleichsam ein Entwicklungsland im heutigen Sinne geworden, eine Interessensphäre jedenfalls der zum Kriege rüstenden europäischen Großmächte. Insbesondere das Deutsche Reich hatte sich durch jahrzehntelange politische und militärische Unterstützung einen nützlichen und strategisch wertvollen Verbündeten gesichert, der im November 1914 an der Seite der Zentralmächte in den Weltkrieg eintrat.

Mohammed V. Resad wurde am 3. Nov. 1844 geboren, war im Jahre 1915 also 71 Jahre alt. Er war der Sohn des einstigen Sultans Abdulmecid I. (1823-1861), aber nicht dessen direkter Nachfolger auf dem Thron. Als Thronfolger galt bei den osmanischen Herrschern seit dem Anfang des 17. Jahrhunderts der jeweils älteste männliche Vertreter des Geschlechtes [5]. Dem Seniorat gemäß bestiegen deshalb zunächst ein Onkel Mohammed Resads, Abdulazis (1830-1876), alsdann zwei ältere Brüder den Sultansthron, nämlich - für ganz kurze Zeit nur - der als geisteskrank erklärte und alsbald wieder abgesetzte Murad V. (1841-1904) und daraufhin, für eine sehr lange Regierungszeit, Abdul Hamid II. (1842-1918; vgl. S. $136^{2}$ sowie die Stammtafel S. 123).

Sultan Mohammed V. war 1909 im Zuge der jungtürkischen Revolution inthronisiert worden. Dank seiner Solidarität war er ein äußerst wertvoller Repräsentant des neuen Regimes und sollte seinen reaktionär gesinnten Vetter und unmittelbaren Thronfolger (vgl. S.128) um jeden Preis überleben. Zu seiner Erhaltung erbat man sich deshalb gerne die Hilfe eines so berühmten und fähigen Arztes, wie ihn das verbündete Deutschland in der Person von Prof. Israel anzubieten hatte.

Die Geschichte der Jungtürkenbewegung geht in das Jahr 1891, wenn nicht noch weiter, zurück. Damals nämlich wurde in Genf das Comité «Union et Progrès» (türk. «Ittihad i Terakki») gegründet, welches sich später auch von Paris aus betätigte und 1906, als die Unterwanderung im Heimatland, insbesondere im osmanischen Heer, weit genug gediehen war, nach Saloniki übersiedelte. Von dort aus gelang es dem Comité 1908, zwei 


\section{Die letzten osmanischen Sultane und ihre Thronfolge}
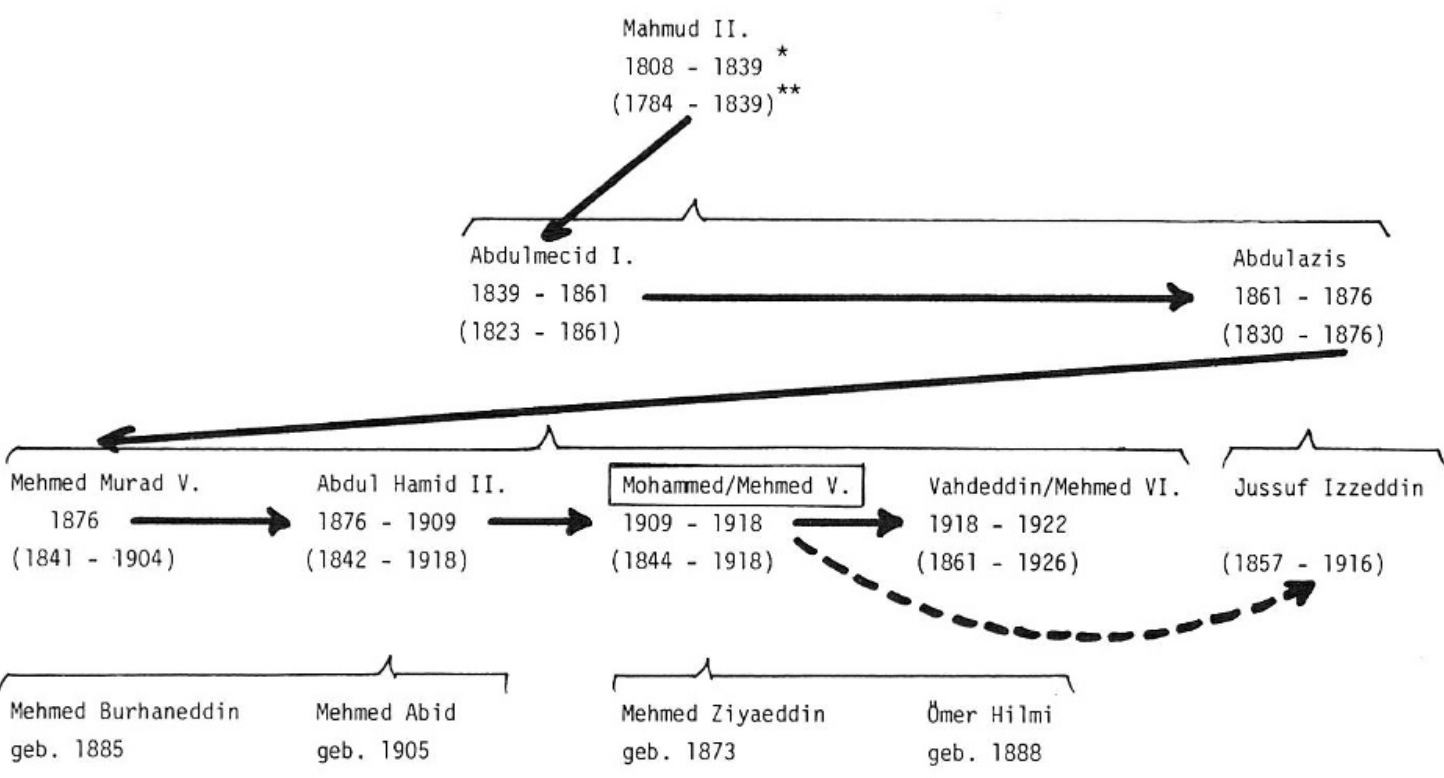

ॠ Regierungszeit ${ }^{\star \star}$ Lebenszeit

mazedonische Armeekorps auf Konstantinopel in Bewegung zu setzen und die Revolution auszurufen. Abdul Hamid II. hoffte zwar, dieselbe äußerlich abzufangen durch die Einsetzung eines liberalen Großwesirs (Ministerpräsident) in der Person von Kücük Said Pascha (1835/38-1914) und durch die Erneuerung der längst in Vergessenheit geratenen konstitutionellen Form der Monarchie von 1876. Inzwischen aber benützte er jede erdenkliche Intrige, um die unliebsamen Neuerer unter sich zu entzweien und seinerseits eine Militärrevolte anzuzetteln. Diese wurde jedoch von den jungtürkischen Streitkräften zerschlagen und der Sultan am 14. April 1909 gefangengenommen, abgesetzt und nach Saloniki, später nach Brussa in Kleinasien verbannt. Irgendeinmal während des Weltkrieges ist er unauffällig in die Hauptstadt zurückgekehrt und 1918 auf Schloß Beylerbey am Bosporus verstorben.

1909 bestieg also der jüngere, völlig unvorbereitete und ahnungslose Bruder Resad als Mohammed V. den osmanischen Thron. Die eigentliche Macht übte jedoch hinfort das Comité für Einheit und Fortschritt aus. 


\section{Vorgeschichte und Antritt der Reise}

Zu Beginn seines Tagebuches schildert Israel unumwunden, wie die Hohe Pforte Verbindung zu ihm suchte. Es war dies die Aufgabe des osmanischen Botschafters in Berlin, Mahmud Moukhtar Pascha, welcher am 10. Juni 1915 telephonisch den Wunsch äußerte, Israel möge ihn in einer dringenden Angelegenheit aufsuchen. Die persönliche Unterredung fand noch am selben Tag statt und gipfelte in der Bitte um eine ärztliche Konsultation beim Sultan. «Es handle sich ... um eine schwere Blasenstörung, wahrscheinlich auf Grund von Steinen.» (p. 1) ${ }^{3}$

Man staunt ob der Dringlichkeit des Ansinnens; Israel sollte nämlich am selben Tage noch abreisen. Dies war indessen erst am folgenden Tage möglich. Immerhin gelang es innert Stunden, vom Auswärtigen Amt einen Regierungspaß und durch die türkische Botschaft Transitvisa für die Durchreiseländer zu beschaffen. Problematisch erschien vor allem das vorderhand neutrale, aber Entente-freundliche Rumänien, das nur den Transitverkehr zwischen Österreich-Ungarn und Bulgarien zuließ. Dabei ist zu bedenken, daß die einzige Bahnverbindung, auch für Militärpersonen, durch Rumänien führte und daß Kriegsmaterialtransporte nach der Türkei nur dank m. o.w. geduldetem Schmuggel möglich waren. Die Bahnverbindung Nisch-Sofia bzw. -Saloniki wurde erst nach der Niederwerfung Serbiens, d.h. ab Januar 1916, für die Zentralmächte benützbar. Daß Rumänien erst im August 1916 an der Seite der Ententemächte in den Krieg eintreten würde, konnte im Jahr zuvor noch niemand wissen. Wie die Neutralität dieses Landes im allgemeinen, so war im besonderen Israels Rückreise eine höchst ungewisse Sache.

Nicht weniger bemerkenswert als die eilige Beschaffung der Reisedokumente erscheint auch, auf wie kurze Frist Israel seine Patienten in stellvertretende Hände übergeben und sein Operationsprogramm annullieren mußte.

Die Bahnreise von Berlin-Zoologischer Garten bis Konstantinopel dauerte vom 11. Juni 16.20 bis zum 17. Juni $2.30 \mathrm{Uhr}$. Sie war mit Umsteigen bzw. Aufenthalt verbunden in Budapest, an der rumänischen Grenze, in Bukarest (Übernachtung), bei der Donaü̈berfahrt und in Sofia. In Konstantinopel wurde Israel empfangen vom Leibarzt des Sultans, Divisionsgeneral Hairi Pascha, und vom Generalstabsarzt der osmanischen Armee, Exz. Suleiman Noueman Pascha. Seine Wohnung erhielt er im Tschit Kiosk, einem «der vielen Palais, aus denen sich der Complex des Yildiz zusammen- 
setzt» (p.10), der Sommerresidenz des Sultans also, im Norden der Stadt gelegen.

\section{Erste ärztliche Kontakte}

Während die ärztlichen Fähigkeiten sowie die menschlichen Qualitäten des Leibarztes Hairi Pascha auf Israel nie sonderlichen Eindruck machten, hielt er Suleiman Noueman Pascha für «eine der sympathischsten Erscheinungen ..., mit welchen ich in Berührung gekommen bin. Er ist ein muhammedanischer Albanier ${ }^{4}$, unverheiratet, Ende der Dreißiger, sehr schlank, mit sehr eleganten Manieren, ein vollendeter Gentleman. Er spricht ziemlich gut deutsch, da er in Deutschland, besonders unter Leyden ${ }^{5}$, studiert hat. Er ist ein sehr intelligenter, gut ausgebildeter Internist und Professor der allgemeinen Pathologie an der Faculté de Médecine. Er hat sich während des Krieges ${ }^{6}$ besonders mit der Immunisierung gegen Flecktyphus beschäftigt, indem er inaktiviertes Blut von Flecktyphuskranken Gesunden einspritzte. Er selbst hat im Kaukasus den Flecktyphus überstanden.» (p. 14)

Von den beiden Balkankriegen (1912/13) her war die türkische Armee stark mit Flecktyphus durchseucht. Auch in dieser Angelegenheit war es in erster Linie Deutschland, welches medizinische Experten entsandte. Als die Hervorragendsten derselben sind zwei Mitglieder des Hamburger Tropeninstituts zu nennen, nämlich der Böhme Stanislaus von Prowazek (1875-1915) und der Brasilianer Henrique da Rocha Lima (1879-1956), welche 1914 im Spital von Haidar Pascha ${ }^{7}$ eingesetzt waren $[6,7,8]$.

Der Generalstabsarzt Suleiman Noueman blieb auch in späteren Jahren mit Israel in Verbindung. So erhielt er dessen Grüße aus Berlin durch Wilhelm His jun. (1863-1934), der 1917 als beratender Internist der deutsch-türkischen Streitkräfte den Orient bereiste [9].

Dem Kollegium, welches sich noch am Morgen seiner Ankunft mit Israel beriet, gehörten außer Hairi und Suleiman weitere prominente Ärzte an, die alle über europäische Bildung und Ausbildung verfügten. Akhil Mouktar, Professor der inneren Medizin, hatte in Genf und Paris studiert. Der Chirurg Orhan Bey, Chefarzt am Deutschen Hospital in Konstantinopel, war Schüler von Max Schede (1844-1902) in Bonn und von Carl Sick in Hamburg. Der Urologe Pappa war Assistent bei Jean Casimir Felix Guyon (1831-1920) und bei Joaquin Maria Albarran y Dominguez (1860-1912) in Paris gewesen. Auch der Otologe Nicolas Taptas (1871-1955), der nachma- 
lige Leibarzt Kemal Atatürks (1880-1938), hatte sich in Wien, Halle, Berlin und Paris spezialisiert $[10,11,12]$.

\section{Antrittsbesuch beim Sultan}

Nach Abschluß der Beratungen wird Israel unverzüglich zum Sultan geleitet. Sabit Bey, der Obergarderobier, spricht ein gutes Französisch und spielt den Dolmetsch. «Der Sultan ist ein kleiner, früher sehr fettleibiger ... Mann von blasser, etwas ins Graue spielender Gesichtsfarbe ...

Trotz der großen Hitze liegt der Sultan ganz in Flanell gekleidet im Bette.

Es erfordert einiges Parlamentieren, ehe er mir gestattet, seine Prostata per anum zu untersuchen, eine Vergünstigung, die seine Ärzte bisher niemals haben erreichen können. Die Prostata ist vergrößert, ohne Zeichen maligner Degeneration. Die Anamnese ergibt, daß die ersten Blasenbeschwerden circa 15 Jahre zurückdatieren. Jetzt muß er unter Schmerzen ca 40 mal in 24 Stunden urinieren ... Die 24stündige Urinmenge beträgt ca. $3000 \mathrm{ccm}$ mit einem spezifischen Gewicht von 1004-1005. Der Urin ist sehr trüb, enthält reichlich Eiter und ist abwechselnd schwach sauer oder alkalisch; früher war Zucker und Aceton vorhanden, jetzt nicht. Er mußte bis jetzt dreimal täglich katheterisiert werden, wobei immer ein Rückstand von ca $300 \mathrm{ccm}$ gefördert wird. Einige Male hat er sehr heftige Blasenblutungen gehabt, welche die Blase vollkommen mit Gerinnsel verstopften. Die Blutungen sollen geradezu profus gewesen sein und konnten erst durch Aspiration der Gerinnsel zum Stillstand gebracht werden. Er ist zur Zeit subfebril, die Abendtemperaturen gehen bis $38^{\circ}$ und darüber; der Puls ist stets frequent, bei Normaltemperatur beträgt er ca. 90, auch darüber, bei ganz leichter Temperaturerhöhung steigt er auf 120.

Eine Röntgen-Aufnahme zeigte zwei sehr große Steine in der Blase, beide gleich gro $\beta$, von annähernd eiförmiger Gestalt, mit einem Längsmesser von $5 \mathrm{~cm}$, einem Höhenmesser von $4 \mathrm{~cm}$. Er hat in der letzten Zeit suburämische Zustände gehabt, Schlafsucht, belegte, trockene Zunge und Lippen, bläuliche Farbe der Schleimhäute, absolute Appetitlosigkeit, Paraesthesien in den Füßen.

Der Zustand war so bedrohlich, da $\beta$ man beschlo $\beta$, eine auswärtige Autorität zu berufen. Der Leibarzt Hairi Pascha legte, um eine gegenseitige Beeinflussung zu vermeiden, jedem der drei tüchtigsten Ärzte des Sultans besonders die Frage vor, wen er für die geeignetste Persönlichkeit halte. Nachdem der Urologe Pappa, der Chirurg Orhan Bey und der Internist Suleiman Noueman sich unabhängig voneinander übereinstimmend für mich ausgesprochen hatten, 
wurde ich berufen ... Ich fand im allgemeinen Zustimmung mit der Erklärung, daß eine Steinzertrümmerung umöglich sei in Anbetracht der Größe der Steine, welche eine sehr lange Sitzung mit entsprechend langer Narkose erfordern würden; ferner in Anbetracht der sehr starken Pyelonephritis und endlich der Schwierigkeiten infolge der starken Prostata-Hypertrophie. Indiciert sei also eine Sectio alta mit langdauernder Drainage der Blase zu dem Zwecke der Entlastung der Nieren. Ehe ich mich aber zu einer Operation entschließen könne, müsse ich erst einige Tage den Patienten beobachten, um mir ein richtiges Bild von seiner Widerstandsfähigkeit zu verschaffen. Bis dahin solle die Blase mindestens zweimal täglich mit dem Katheter entleert und gespült werden.» (pp. 17-20)

\section{Regierungsspitzen und Mitglieder der Sultansfamilie}

Anschließend an diese erste Konsultation wird Israel dem versammelten Ministerkollegium vorgeführt. Als Anwesende erwähnt er den Großwesir, den Justizminister Ibrahim Bey, den Innenminister Talaat Bey, den Kriegsminister Enver Pascha und den Scheich ul Islam. Letzterer «trug als einziger unter den Anwesenden die alttürkische Tracht: einen gegürteten schwarzen Kaftan und einen weiß umwickelten Turban ... Er ist der höchste geistliche Würdenträger und zugleich die oberste Instanz der geistlichen Gerichte (Scheria).» (p.31)

Den Vorsitz im Ministerrat hatte zu jener Zeit (1913-17) der Großwesir Said Halim Pascha (1863-1921), ein konservativer Staatsmann von geringem Einfluß und - eher Entente-freundlich - vom Kriegseintritt seines Landes nicht eben begeistert. Als Enkel Mehmed Alis (1769-1849) und Vetter des einstigen Khediven Ismail (1830-1895) betrachtete er sich noch stets als ägyptischen Kronprätendenten, denn die halimische Linie des Khedivenhauses anerkannte den 1866 vorgenommenen Wechsel zur Primogenitur noch immer nicht, sondern hielt am Seniorat fest. Letzteres war zwar soeben (1914) wieder eingeführt worden, aber eben nur innerhalb der Nachkommen regierender Khediven.

«Seine Hoheit der ägyptische Prinz Said Halim Pascha ist ein kleiner, elegant gekleideter Mann von distinguiertem Äußern ... Er spricht vollendet französisch und ... ist mir gegenüber von großer Liebenswürdigkeit, aber sein Gesicht, welches keinerlei mimische Bewegung zeigt, erscheint undurchdringlich; was hinter dieser kalten Maske vorgeht, kann keiner erraten.» p. 31) 
Der aus der Gegend von Adrianopel stammende Mehemed Talaat Bey (1872/74-1921) hatte sich als junger Telegraphenbeamter der revolutionären Bewegung angeschlossen und wurde neben Enver zur führenden Person in der jungtürkischen Partei. Nach der Revolution von 1909 wurde er Innenminister, 1911-12 vorügergehend Postminister. Im Februar 1917 folgte er Said Halim Pascha als Großwesir - der erste Jungtürke in der Stellung des Ministerpräsidenten. Er "gilt für den fähigsten Kopf unter den Ministern. Er ist der eigentliche Leiter der Politik. Er ist ein breitschultriger, etwas korpulenter, ein wenig plebejisch aussehender Mann ... Er spricht ganz schlecht französisch, weil er es erst angefangen hat zu erlernen, als er Minister wurde. Er ist ganz und gar ein self-made-man ...» (p.32)

"Der Kriegsminister Enver hat ein auffallend hübsches Mädchengesicht, wozu seine Schüchternheit in der Unterhaltung paßt, trotzdem erkennt man in ihm einen energischen, zielbewußten Mann. Er ist 32 (?) Jahre alt, eine schlanke, elegante Erscheinung, spricht gut deutsch und französisch und macht einen offenen, sehr sympathischen Eindruck.» (p.32)

Enver Pascha (1881-1922) war das älteste von sechs Kindern eines kleinen Beamten aus Monastir in Mazedonien. Er absolvierte die Militärschule von Pankaldi und wurde Generalstabsoffizier. In Mazedonien stationiert, schloß er sich der jungtürkischen Bewegung an und wurde zu einer Hauptfigur in der Revolution von 1908. 1909 bis 1911 weilte er als Militärattaché in Berlin und gewann dort starke Sympathien für das Deutschtum und den preußischen Militarismus. 1912 wurde er Generalsekretär seines Freundes Talaat und 1914, nach der Ermordung des Großwesirs Chevket Pascha, Kriegsminister im Kabinett Said Halim. Im Dezember 1914 führte er die 3.türkische Armee von Armenien aus gegen die Russen. Nach dem unheilvollen Ausgang dieses Feldzuges mied er jedoch fortan die Rolle des aktiven Heerführers. - Er war mit einer Nichte des Sultans verheiratet.

An einem der ersten Tage seines Aufenthaltes empfing Israel den ältesten Sohn des Sultans, den 42jährigen Mehmed Ziyaeddin (geb. 1873). Dieser war nicht etwa Thronfolger. Dem Seniorat gemäß kam diese Würde Jussuf Izzeddin (1857-1916), einem Vetter des Sultans, zu. Izzeddin, welchen Israel später ebenfalls persönlich kennenlernte, war ein neurotischer, unberechenbarer, konservativer und dem Regime feindlich gesinnter Prinz. Die deutschfreundlichen Jungtürken setzten daher alles daran, den kränklichen Mohammed V. am Leben zu erhalten und Izzeddins Thronbesteigung so lange als möglich zu verhindern. 1916 verstarb Jussuf Izzeddin jedoch 
unerwartet - angeblich durch Selbstmord. Damit war die reaktionäre Gefahr gebannt. In der Person seines jüngeren Bruders Vahdeddin (1861-1926) hatte Mohammed V. wieder einen regimetreuen, deutschfreundlichen Kronprinzen zur Seite, welcher 1918 als Mehmed VI. und als letzter osmanischer Sultan den Thron bestieg und denselben noch bis 1922 innehatte.

An weiteren lebenden Söhnen Mohammeds V. traf Israel den Prinzen Ömer Hilmi (geb. 1888); auch dem jüngsten Sohne Abdul Hamids, Mehmed Abid (geb. 1905), wurde er bei Gelegenheit vorgestellt. Eine der sechs lebenden Töchter Abdul Hamids zählt zu den wenigen türkischen Damen, welche Israel bei besonderer Gelegenheit unverschleiert gegenübertreten durften.

\section{Die Stellung der türkischen Frau bei Hofe und in der Gesellschaft}

"Mit Erlaubnis des Sultans besuchte ich heute (26. Juni) den Haremsgarten ... Ich war der erste Fremde, der das geheiligte Gebiet betreten hat. Noch manche andere Vorkommnisse ereigneten sich zum ersten Male während meines Aufenthaltes ..., denn es war das erste Mal, daß ein Sultan operiert worden ist, und das erste Mal, daß ein fremder Mann sich in einer Gesellschaft unverschleierter türkischer Damen befunden hat.» (p. 70)

«Das Ereignis des heutigen Tages (1. Juli) ist ein Wohltätigkeitsfest, welches die Damen zu Gunsten der Armee im Taximgarten veranstalten. Bis 8 Uhr abends ist es ausschließlich für Damen zugänglich. Dieses Fest war in doppelter Hinsicht ein Ereignis, denn es war erst das zweite Mal in der Geschichte der Türkei, daß muselmänische Damen ein öffentliches Lokal betreten haben. Vordem ereignete es sich nur noch an dem Tage bei der Verkündigung der Konstitution, aber es war das erste Mal, daß einem Manne der gesellschaftliche Zutritt zu einem Kreise unverschleierter anständiger Damen gewährt wurde, denn ich hatte den Vorzug, eingeladen worden zu sein. Man betrachtete mein Erscheinen als eine hohe Ehre; alles umdrängte mich und machte mir die Cour, soda $\beta$ ich Cercle wie ein Souverain halten mußte.» (p. 86)

«Nach dem Abendessen begab ich mich zum zweiten Male nach dem Wohltätigkeitsfest im Taxim, das von 9 Uhr abends für Herren geöffnet war. Infolgedessen waren die unverschleierten türkischen Damen verschwunden und wurden an ihrer Stelle Verkaufsbuden, Buffets und Gäste durch griechische, christliche, armenische und israelitische Damen bedient.» (p.90) 
"Alle Damen, mit denen ich mich unterhalten habe, unterschieden sich weder in ihrem Benehmen, noch in der Gewandtheit der Unterhaltung von ihren europäischen Schwestern, sodaß ich den Eindruck hatte, daß das Haremsleben in den höheren Ständen nicht notwendig unvereinbar sei mit Bildung und gesellschaftlicher Gewandtheit. Allerdings ist die Frauenbildung erst ein Produkt der neuen Zeit, welche im Zeichen der jungtürkischen Bewegung steht. Bei den älteren Damen sieht es noch sehr schlimm damit aus. So kann z. B. die erste Frau des Sultans, die Basch-Kadine weder lesen noch schreiben, dagegen wird jetzt für gute Mädchenschulen gesorgt.» (p.87/88)

«Beim Fortgehen traf ich im Erdgescho $\beta$ den Prinzen Hilmi, als er gerade aus einem Zimmer des Harems heraustrat. Er wollte mich ansprechen und vergaß die Tür zu schließen. Diese seltene Gelegenheit benutzten einige Damen um sich in die offene Tür zu drängen und mich zu betrachten, trotzdem der Eunuch des Prinzen dabei stand. Das war das einzige Mal, daß die Frauen nicht sofort weggejagt wurden, wenn ein fremder Mann in Sicht war.» (p. 150)

«Mit dem jetzigen Sultan hat die barbarische Sitte des Eunuchentums ein Ende. Neue werden nicht mehr hergestellt. Die jetzt noch vorhandenen hat er aus dem früheren Hofhalt seines Bruders übernommen. Alle Eunuchen des jetzigen Hofes sowie die meisten überhaupt sind Abyssinier, welche in frühen Jahren in ihrer Heimat verschnitten wurden. Ein großer Teil stirbt an der Verletzung; die $\ddot{U}$ berlebenden werden an den Hof des Sultans oder an andere Haremsbesitzer verkauft. Das Verschneiden besteht nicht in der einfachen Kastration, sondern es wird das ganze äußere Genitale, Glied mit Hodensack und Inhalt durch einen Schnitt abgetrennt. So bilden sich in bezug auf die Harnröhrenmündung weibliche Verhältnisse aus, dementsprechend die Eunuchen nur im Sitzen urinieren können. Aber infolge der Durchschneidung ohne Umsäumung der Schleimhaut tritt häufig eine Verengung des Harnröhrenausganges ein, welche durch Stauung zur Infektion der Blase und der Nierenbecken führt, dem viele in späteren Jahren erliegen.» (p. 74)

\section{Vorbereitungen zur Operation}

Am 19. Juni «um 3 Uhr Nachmittag erhielt ich den Besuch von Enver Pascha. ${ }^{8}$ ... Er nimmt durch sein angenehmes Äußeres sofort für sich ein. Natürlich kamen wir auf die bevorstehende Entscheidung über die Operation zu sprechen. Als ich ihm sagte, daß die heute vom Großwesir betonten, ernsten politischen Konsequenzen eines unglücklichen Ausgangs der Operation meinen Entschlu $\beta$ 
naturgemä $\beta$ erschwerten, sprach er als Soldat, der vor einem kühnen Unternehmen nicht zurückschreckt: «Bei Ihnen ganz allein mu $\beta$ die Entscheidung liegen. Wir alle verstehen nichts davon. Tun Sie also ganz, was Ihnen gut dünkt.» (p. 48)

Am 20. Juni findet wiederum ein Konsilium aller beteiligten Ärzte statt. Einstimmig schließt man sich der Auffassung Israels an, der dringend zur Operation rät. Ein entsprechendes Protokoll wird abgefaßt und dem Ministerkollegium übersandt. Bei der Morgenvisite des 22. Juni fragt Israel endlich den Sultan selbst um seine Einwilligung zur Operation. Sie wurde «ohne Zögern erteilt» (p.57). Zu seiner engeren Umgebung soll der Sultan anschließend gesagt haben, «er fürchte sich nicht vor dem Tode, denn so möchte er nicht weiterleben. Er könne sich nicht bewegen, er leide dauernd Schmerzen und könne seinem Lande nichts nützen.» (p.57)

Israels unmittelbare Sorge gilt nun den Vorbereitungen zur Operation. Am 22. Juni «fuhr ich mit Orhan Bey in der kaiserlichen Mouche nach dem in Skutari gelegenen ... Senep-Kiamil Hospital, ... um einen geeigneten Operationstisch zu finden ... Als Ärzte fungieren Dr. Aschheim, Assistent von Geheimrat Franz ${ }^{9}$ und Dr.Schwalbe, Assistent an der Kinderklinik der Charité.» (p.57)

Selmar Aschheim, geb. 1878 in Berlin, 1902 zum Dr.med. promoviert in Freiburg i.B., wurde Leiter des Laboratoriums an der Frauenklinik der Charité. 1931/32 erhielt er einen Lehrauftrag für biologische Forschung im Dienste der Gynäkologie und wurde Honorarprofessor. Er emigrierte 1936 nach Paris, wo er 1965 starb [13, 14, 15]. Gemeinsam mit Bernhard Zondek (1891-1966) entdeckte Aschheim die Ausscheidung von Choriongonadotropin im Urin der Schwangeren, welcher, juvenilen Mäusen injiziert, Oestrus hervorruft und so zur Diagnose der Schwangerschaft diente $[16,17,18]$.

Dr.Schwalbe läßt sich nicht zweifelsfrei identifizieren. Aller Wahrscheinlichkeit nach handelt es sich um Markus Walter Schwalbe, geb. 1883 als Sohn eines Berliner Fabrikanten. Er studierte Medizin in München, Straßburg und Berlin und promovierte 1908 an der neurologischen Klinik der Charité bei Theodor Ziehen (1862-1950) mit einer Arbeit über «Eine eigentümliche Krampfform mit hysterischen Symptomen» bei drei Jugendlichen. Es handelte sich um Dysbasia lordotica progressiva s. Dystonia musculorum deformans $[19,20]$. Die Identität mit dem von Israel genannten, an der Kinderklinik der Charité tätigen Assistenten erscheint demnach naheliegend.

In der Tat fand Israel in dem Hospital «einen geeigneten, ganz modernen Operationstisch und ließ ihn auf unsere Mouche verladen.» (p.58) Am 
folgenden Tage «richtete ich als Operationszimmer einen großen Saal ein, der gleichzeitig dazu bestimmt war, dem Patienten nach der Operation als Schlafzimmer zu dienen ... Da keine Wasserleitung vorhanden ist, mußte für kaltes und warmes Wasser Vorkehrung getroffen werden. Dazu fanden sich als sehr geeignete Apparate ein halbes Dutzend Riesen-Samoware, deren jeder mindestens 30 Liter faßte ... Diese Samoware wurden im Vorzimmer des Operationssaals auf einem Tische aufgestellt, vor jedem eine Waschschüssel. Die Instrumente hatte ich aus dem Deutschen Hospital und aus dem Besitze von Dr. Pappa ausgewählt. Ein besonderes Zimmer diente als Sterilisationsraum, wo zwei mit Spiritus zu heizende Instrumentenkocher aufgestellt waren ... Wäsche und Verbandstoffe kamen sterilisiert aus dem Deutschen Krankenhause. Drei deutsche Schwestern wurden verpflichtet; nämlich die Operationsschwester des Deutschen Krankenhauses zum Instrumentieren und zwei zur Pflege, davon eine aus dem Deutschen Hospital, die andere aus dem Krankenhause der Fakultät. Beide sprachen türkisch ... Für Sauerstoff-Apparate, physiologische Kochsalzlösung, Kampfer und Coffein war gesorgt, ebenso für Instrumente zur Tracheotomie im Falle einer Asphyxie bei der Narkose.» (p.59/60)

\section{Diplomatische und andere zivile Vertreter Deutschlands in Konstantinopel}

Israel nutzte außerdem seine Zeit, mit den verschiedensten Landsleuten Verbindung aufzunehmen, in erster Linie mit dem Botschafter von Wangenheim. "Er empfängt mich sehr liebenswürdig. Er macht einen sehr nervösen und abgearbeiteten Eindruck. Seine Gesichtsfarbe ist ungesund grau.» (p.60)

Hans Freiherr von Wangenheim, geboren am 8. Juli 1859, verließ als Rittmeister den militärischen Dienst, um die diplomatische Laufbahn zu betreten. Schon 1899-1904 war er als Botschaftssekretär in Konstantinopel tätig gewesen. Ein besonderer Günstling des Kaisers Wilhelm II., wurde er u. a. Gesandter in Griechenland, dessen König eine Schwester des deutschen Kaisers zur Frau hatte. Im Jahre 1911 schließlich gelangte von Wangenheim als Botschafter nach Konstantinopel und trat so die Nachfolge des Freiherrn Adolf von Bieberstein (1842-1912) an.

«Als Wangenheim den Posten in Konstantinopel antrat, war er schon schwer leidend ... Im Juli 1915 sah sich W. gezwungen, um einen zweimonatigen Erholungsurlaub nach Deutschland zu bitten, während welchem ihn Fürst Ernst zu Hohenlohe-Langenburg $(1863-1950)^{10}$ vertrat und von 
welchem er anfangs Oktober nach Konstantinopel zurückkehrte. Sein Zustand hatte sich aber nicht gebessert, sondern war im Gegenteil ernster geworden. Am 23. Oktober erlitt er einen Schlaganfall, welchem er noch am selben Abend erlag. Die Leiche Wangenheims wurde am 26.Oktober zur Ruhe bestattet ... Nach einer einfachen Zeremonie ... wurde er im Garten der deutschen Sommerresidenz an der Seite seines Jugendfreundes, Oberst Leipzig, begraben» [21]. In demselben Park sollte übrigens auch im folgenden Jahre die aus Bagdad dahin überführte Leiche des Generalfeldmarschalls von der Goltz bestattet werden [21, 22].

Der mysteriöse Todesfall des Obersten von Leipzig, des deutschen Militärattachés, hatte sich am 28. Juni 1915, also gerade während Israels Aufenthalt in Konstantinopel, ereignet. "Er hatte das Unglück, bei der Rückkehr von einer Reise zur Front von Gallipoli durch Selbstentladung seines Revolvers getötet zu werden. Der Hergang wurde so erzählt, daß er sich zur Rückfahrt Zivilkleider anziehen wollte und, um den Zug nicht zu versäumen, eiligst die Uniform und den geladenen Revolver in den Koffer warf; durch die Erschütterung ging die Sicherung los, die Kugel durchscho $\beta$ das Etui und drang in den Schädel. Der Tod trat nach 6 Stunden ein. Er war eine sehr geschätzte Persönlichkeit und eine große Stütze für die Botschaft. Die Aufbahrung und die Trauerfeier fanden in dem Garten der Botschaft statt.» (p.81)

Von Leipzigs Nachfolger war der Oberst von Lossow. Dieser war während mehrerer Jahre Professor an der türkischen Militärakademie gewesen und hatte dann an den Balkankriegen teilgenommen. Nach Deutschland zurückgekehrt, wurde er im Juli 1915 als Militärattaché nach Konstantinopel berufen und stieg später bis zum Generalleutnant auf [21]. «Der Militärbevollmächtigte von Lossow ist Bayer; er ist ein auffallend langer, hagerer Mann mit ungewöhnlich schlecht und schlotterig sitzender Uniform. Er soll ein sehr guter Offizier sein, wie mir Mashar Bey sagte, der sein Adjutant im Balkankrieg gewesen war.» (p. 145)

Als Botschaftsrat stand dem Botschafter der Freiherr Konstantin von Neurath zur Seite. Er war der Sohn des Oberstkammerherrn im württembergischen Königshaus, hatte in Tübingen und Berlin die Rechte studiert und trat zunächst in den württembergischen Justizdienst, alsdann (1901) als Assessor ins Berliner Auswärtige Amt ein. 1903 ging er als Vizekonsul nach London, 1908 wiederum ans Auswärtige Amt und 1914 als Botschaftsrat nach Konstantinopel. Nach dem Kriege war er deutscher Gesandter bzw. Botschafter in Kopenhagen, Rom und London. Ein Vertrauensmann Hindenburgs, war er von 1932 an Reichsaußenminister in den Kabinetten 
von Papen, Schleicher und Hitler. Von Joachim von Ribbentrop (1893-1946) verdrängt und zum Minister ohne Portefeuille ernannt, wurde er sodann im März 1939 Reichsprotektor im besetzten Böhmen und Mähren, wurde jedoch ab 1941 in dieser Eigenschaft von seinem Stellvertreter Reinhard Heydrich (1904-1942) faktisch abgelöst. 1946 wurde er im Nürnberger Hauptprozeß zu 15 Jahren Gefängnis verurteilt, 1954 jedoch aus der Spandauer Haft vorzeitig entlassen. Er starb am 14. August 1956 in Enzweihingen/Württemberg.

In der deutschen Botschaft verkehrten auch einige Journalisten, vorab der Dichter Herbert Eulenberg (1876-1949), vormals Dramaturg am Deutschen Theater in Berlin, dann am Schauspielhaus in Düsseldorf. Er verfaßte eine ganze Reihe neuromantischer Dramen und vielerlei Erzählungen, meist biographischen Inhalts. Für sein Trauerspiel «Belinde» erhielt er 1912 den Schillerpreis. Bis 1933 war er einer der meistaufgeführten deutschen Bühnenautoren. Vom Dritten Reich ignoriert, wurde er 1946 Ehrenbürger der Stadt Düsseldorf und gewann 1949 den Nationalpreis der Deutschen Demokratischen Republik.

Als Kriegsberichterstatter hielt sich Karl Georg Vollmöller in der deutschen Botschaft auf. Der 1878 geborene Sohn des Romanisten Karl Vollmöller (1848-1922) entstammte einer angesehenen Dynastie von Textilfabrikanten in Vaihingen bei Stuttgart. Er studierte Archäologie und klassische Philologie in München, Paris, Athen und Bonn, wo er 1901 zum Dr. phil. promovierte. Unter seinen zahlreichen Bühnenwerken wurde die pompöse, von Engelbrecht Humperdinck (1854-1921) vertonte und 1914 von Max Reinhardt (1873-1943) im Berliner Zirkus Busch uraufgeführte Pantomime «Das Mirakel» (vgl. p.94) ein Welterfolg. Mit ihrem Aufwand von über 2000 Mitwirkenden bedeutete sie den Höhepunkt des neuromantischen Revuetheaters. Daneben war Vollmöller auch Automobilkonstrukteur, Sportflieger und ein Pionier des Films. Ein dandyhafter Kosmopolit, lebte er abwechslungsweise in Berlin, Paris, Sorrent (1905), Mailand (1910), Hollywood und Basel (1938/39, 1948). 1935 bewohnte er kurz den Palazzo Vendramin, das Sterbehaus Richard Wagners, in Venedig. Er starb 1948 in Los Angeles.

Des weiteren erwähnt Israel einen gewissen Alfred Lichtheim mit Gattin (p. 76, 91). Es dürfte sich jedoch um Richard Lichtheim (1885-1964) gehandelt haben, denn dessen Vater Alfred war schon 1908 verstorben [24]. Richard Lichtheim war ein Pionier des deutschen Zionismus [25] und vertrat während des Ersten Weltkrieges die zionistische Weltorganisation in Kon- 
stantinopel. Seine Frau Irene geb. Heffter entstammte einer jüdischen Familie in Konstantinopel.

An dieser Stelle ist auch ein Amerikaner anzufügen, dessen Bekanntschaft Israel machte, nämlich Henry Morgenthau (1856-1946). Ohne jegliche diplomatische Vorbildung war dieser 1913 US-Botschafter in Konstantinopel geworden und vertrat dort auch die Interessen mehrerer kriegführender Staaten [26]. Späterhin (1923) präsidierte er die Völkerbundskommission für die Umsiedlung der aus Kleinasien vertriebenen Griechen [27] und intervenierte wiederholt gegen die türkische Unterdrükkung der Armenier. "Morgenthau, ein aus Mannheim gebürtiger Israelit, ist hier sehr beliebt und hoch geschätzt, da er viel Gutes wirkt.» (p. 82)

\section{Die Operation}

Am 24.Juni 1915 «um 9 Uhr morgens findet die Operation statt. Die persönliche Assistenz haben Orhan Bey und Pappa übernommen. Die ÄtherNarcose wird von Refik Bey ${ }^{11}$ ausgeführt. Anwesend waren Hairi Pascha, Suleiman Noueman, Akhil Moukthar, Taptas. Die Narkose verlief nach einer vorher verabfolgten Pantopon-Einspritzung sehr ruhig.

Nach Füllung der Blase mit Luft wurde die Sectio alta ausgeführt und zwei sehr große Steine entfernt. Beide sind ungefähr gleich groß, eiförmig, im längsten Druchmesser $5 \mathrm{~cm}$, im kürzesten $4 \mathrm{~cm}$. Die Abtastung der Blase ergab eine sehr große intravesikal entwickelte Prostata, die unter günstigeren Widerstandsverhältnissen eine Indikation zur Exstirpation gegeben haben würde. Aber in Anbetracht der bedrohlichen Nierenaffektion mußte ich davon Abstand nehmen. Mit Rücksicht auf eine Entlastung der kranken Niere durch einen permanenten Abflu $\beta$ drainierte ich die Blase durch ein dickes Rohr. Die Blasenwunde wurde bis auf die Öffnung für das Drainrohr ${ }^{12}$ vernäht; ebenso die Bauchdecken. Die Umgebung des Drainrohres wurde durch einen kleinen Jodoform-Gazestreifen tamponiert.

Der Patient vertrug die Narkose vortrefflich, brach nicht, hatte keine Störung der Plusfrequenz. Er erwachte ziemlich schnell. Der Verbrauch von Äther war sehr gering gewesen, weil ich Wert darauf gelegt hatte, die Operation vor Eintritt einer tiefen Narkose zu beginnen und sie so schnell wie möglich auszuführen.» (p.62)

Am Tage nach der Operation, "als ich vor dem Abendbrot nach dem Taximgarten fuhr, ... sah ich die ganze Stadt aus Anla $\beta$ der gelungenen 
Operation des Sultans Haus für Haus beflaggt. Dieser etwas verfrühte Jubel berührte mich einigermaßen peinlich bei dem Gedanken, daß die mit der Operation verbundene Gefahr naturgemä $\beta$ noch lange nicht als beseitigt gelten konnte. Die Gespenster des Bronchial-Katarrh und der Bronchopneumonie, der Lungen-Hypostase, der Störung der Herz- und Nierenfunktion stiegen vor mir auf und verboten mir, an der Feststimmung der Bevölkerung teilzunehmen. Drei Tage flaggte und illuminierte die Stadt. Erst als der Jubel ausgeklungen war, konnte ich selbst anfangen, zufrieden zu sein, denn als drei Tage lang alles gut gegangen war, durfte ich mich der Hoffnung auf Beseitigung der Lebensgefahr mit einiger Wahrscheinlichkeit hingeben. Wohl aber blieb die fatale Möglichkeit einer nicht zur Heilung kommenden Blasenfistel noch übrig.» (p.67)

Nach rund 14 Tagen, am 7. Juli, war der Sultan denn auch plötzlich «mit Frost und hohem Fieber erkrankt.» (p.111). Als Ursache fand sich eine Epididymitis.

\section{Abdul Hamid und sein Regime}

Fast zwangsläufig äußerte der Patient eines Tages bei der Visite die Frage nach der Entstehung von Harnsteinen. "Ich erklärte ihm in verständlicher Weise, da $\beta$ ihre Bildung in einer Stoffwechsel-Anomalie beruhe, die entweder durch quantitative oder qualitativ unzweckmäßige Ernährung oder durch ungenügende Körperbewegung zustande komme. So blieben infolge der unvollkommenen Ausnutzung der Nahrungsstoffe Schlacken im Körper zurück, aus denen sich die Steine bildeten. Darauf erwiderte der Sultan: Der Grund der unzureichenden Körperbewegung leuchte ihm sehr ein und treffe für ihn zu, denn er sei ja 30 Jahre lang in Dolma Bagsche ${ }^{13}$ eingesperrt gewesen, worauf Sabit Bey die Bemerkung machte: «Ja, es ist so, Abdul Hamid allein ist schuld an der Bildung der Steine.» (p. 101)

"Abdul Hamid hat ihn nicht nur dreißig Jahre lang in einer Art Gefängnis in Dolma Bagsche gehalten, sondern ihn auch in kleinlicher Weise unterdrückt. Wenn der Sultan als Thronfolger ausfuhr, durfte ihn niemand grüßen. Ja, es wurden sogar seinem Bedürfnis nach Bildung Hindernisse in den Weg gelegt. Er sprach einmal sein Bedauern darüber aus, daß er keine europäische Sprache spräche, deren Kenntnis doch für einen Sultan im Verkehr mit den Gesandten fremder Mächte unentbehrlich sei. Er habe darum auch einmal versucht, französisch zu lernen, aber da habe ihm sein Bruder Abdul Hamid den Lehrer fortgenommen und den ferneren Unterricht verboten.» (p. 102) 
Wie der Sultan selbst schilderte, hatte ihm sein Bruder, der konservative, despotische und überaus mißtrauische Abdul Hamid II. (vgl. S. 122), während voller dreißig Jahre auf grausame und primitive Weise das bedauernswerte Schicksal eines zur Untätigkeit verurteilten Gefangenen zugedacht und ihm jegliche persönliche Entfaltung oder Bewährung verunmöglicht. Er betrachtete seinen jüngeren Bruder als Rivalen und versuchte, die Thronfolge im Sinne der Primogenitur zu ändern und seinen Lieblingssohn, Mehmed Burhaneddin (geb. 1885) ${ }^{14}$ dem Bruder vorzuziehen [28]. Als dieser dann endlich im Alter von 65 Jahren - im Gefolge des jungtürkischen Umsturzes 1909 - dem gestürzten Bruder auf dem Thron folgte, war er «ein verbrauchter Mann» (p. 1).

Schon Abdul Hamid hatte deutsche Ärzte an seinen Hof bemüht. Ähnliche Konsultationsreisen wie Israel unternahm einige Jahre vor ihm der führende deutsche Chirurg Ernst von Bergmann (1836-1907) zusammen mit seinem Privatassistenten Richard Bier, und zwar zu zweien Malen, im Mai und im September 1906. Abdul Hamids Lieblingstochter, die sechzehnjährige Refié, litt an appendizitischen Beschwerden, wurde aber nach vielem Hin und Her schließlich doch nicht operiert. Zum einen beharrte von Bergmann nicht auf dem Eingriff; zum andern konnte sich der allzeit mißtrauische Sultan zu keinem Entschluß durchringen. Dies alles, obwohl von Bergmann gleich nach seiner Ankunft eine erfolgreiche Appendektomie ausgeführt hatte, und zwar an einer jüngeren, anscheinend weniger bevorzugten und möglicherweise kerngesunden Prinzessin, die einfach als eine Art «Probiermamsell» herhalten und bestehen mußte.

Mit seinen 70 Jahren ertrug von Bergmann die Strapazen der langwierigen, hindernisreichen Bahnreise und der ungewohnten, üppigen «Schlangenfütterungen», wie er schreibt, ungleich schlechter als Israel, der zwar im Jahre 1915 fast ebenso alt war wie von Bergmann zu seiner Zeit. Doch litt der letztere eben zudem unter dem hinterhältigen Trödel eines wankelmütigen, unentschlossenen Gastgebers. In seinen Briefen und Aufzeichnungen äußert er sich denn auch entsprechend ungnädig und sarkastisch [29].

\section{Deutsche Heerführer und Flottenchefs in der Türkei}

Am 1. Juli «wohnte ich der Trauerfeier für den verstorbenen Oberst v. Leipzig bei ... Es beteiligten sich sämtliche Diplomaten, Militär-Attachés, deutsche und türkische hohe Militärs und Marineoffiziere.» (p.81). An Bedeutung wie an 
Jahren überragte diese alle der Oberbefehlshaber über die deutsch-türkischen Streitkräfte, der Generalfeldmarschall Colmar Freiherr von der Goltz (1843-1916). Er war seit Jahren mit der Türkei verbunden. Schon die Reorganisation der Wehrmacht Abdul Hamids II. im Anschluß an den Berliner Kongreß (1878) war zur Hauptsache sein persönliches Werk in den Jahren 1883-1895. Im Jahre 1909, nach dem jungtürkischen Umsturz, wurde der damalige Armee-Inspekteur erneut für kurze Zeit nach Konstantinopel entsandt. Im Dezember 1914 schließlich, nachdem er kurze Zeit Generalgouverneur im besetzten Belgien gewesen war, wurde ihm der Oberbefehl über die türkisch-deutschen Streitkräfte anvertraut.

Von der Goltz «gibt der Ansicht Ausdruck, daß ein Feldzug gegen Ägypten nicht viel Aussicht habe ... Er meint, daß die verwundbare Stelle der Engländer Indien sei und man sehr wohl einen Einfall in Indien planen könne. Die Möglichkeit eines solchen Vorgehens sei bereits bewiesen durch den erfolgreichen Feldzug eines persischen Schah im 18. Jahrhundert ... Diesen Feldzug, von dem genaue Aufzeichnungen vorhanden sind, hat v.d.Goltz studiert und ist zu der Überzeugung gekommen, da $\beta$ daraus noch heute Verwertbares zu lernen ist. Es gehen zwei Wege von Persien nach Indien, ein nördlicher und ein südlicher. Man müsse diesen letzteren wählen» (p. 64/65).

Mit diesem Endziel vor Augen führte v.d.Goltz seine Streitkräfte siegreich nach Mesopotamien herein und brachte den Engländern bei Kutel-Amara am Tigris 1916 einen vernichtenden Schlag bei. Die Kapitulation des Feindes vom 28. April 1916 ([22]; Mühlmann [30]: 29. April) erlebte er allerdings nicht mehr, denn nach mühsamer Rückreise zu Schiff erlag er in Bagdad in der Nacht vom 18. zum 19. April 1916 dem Flecktyphus. Am 24. Juni wurden seine sterblichen Überreste nach Therapia überführt und im Garten der deutschen Botschaft beigesetzt (vgl. S. 133).

An derselben Trauerfeier "sah im zum ersten Male den Admiral Souchon», Kommandant der deutschen Mittelmeerdivision sowie der türkischen und der bulgarischen Flotte, «dessen energisches Gesicht mit herabgezogenen Mundwinkeln ein wenig an die Züge des Colleoni ${ }^{15}$ erinnert» (p.82). Am Abend des 19. Juli nächsthin «soll das von mir im Tschit Kiosk zu Ehren des Admirals gegebene Diner stattinden. (p.137 ... Mit Souchon, der den beneidenswerten Appetit des Seemanns entwickelte, unterhielt ich mich vortrefflich» (p.139). Am 22. Juli «abends 8 Uhr folgte ich einer Einladung Souchons zum Diner auf dem «General», der jetzt als Wohnschiff für den Stab und die Offiziere der Etappe dient» (p. 144).

Dank dem Geschick des Admirals Wilhelm Anton Theodor Souchon (geb. 
1864) waren die beiden Schlachtkreuzer «Breslau» (6500 t) und «Goeben» (23500 t) sowie das als Hilfskreuzer ausgerüstete Frachtschiff «General» der Ostafrika-Linie anfangs August 1914 der Einkreisung durch britische Einheiten bei Messina entkommen. Sie hatten von Enver Pascha freie Durchfahrt durch die Dardanellen und - am 14. September 1914-Einlaß ins Schwarze Meer erhalten, wo sie im Oktober überraschend und ohne Kriegserklärung türkischerseits den russischen Hafen Theodosia auf der Halbinsel Krim bombardierten. Damit war die seit dem Ende des Krimkrieges (1856) in Kraft befindliche sog. Schwarzmeerklausel, welche die Passage nichttürkischer Schiffe verbot, erstmals wieder gebrochen. Nachdem die EntenteMächte sich bei der Hohen Pforte deswegen beschwert hatten, trat die Türkei kurzerhand als Käufer auf und übernahm die beiden Kreuzer unter den neuen, türkischen Namen «Medillih» und «Javus Selim» mitsamt der ganzen Besatzung, alles Begebenheiten die Israel aus direktester Quelle, d.h. vom Admiral persönlich geschildert bekam.

Im Gefolge von Souchon fand Israel den Flaggoffizier, Oberleutnant zur See von Wichelhaus, sowie den Oberleutnant Kümpel (vgl. unten), ferner den Kommandanten der «Goeben», Kapitän zur See Ackermann, und die Korvettenkapitäne Haas und Humann. Hans Humann (1878-1933), deutscher Marineattaché in Konstantinopel, wurde später Verlagsleiter der Deutschen Allgemeinen Zeitung. Sein Vater war der Archäologe Carl Humann (1839-1896), der Entdecker des Pergamon-Altars. Hans Humann war auch der Schwager von Friedrich Sarré (1865-1945), Rittmeister im Stabe v.d.Goltz' (vgl. S. 138), dann Militärattaché in Teheran und schließlich Professor für Islamistik in Berlin.

"Auf Einladung von Oberleutnant Kümpel besuchte ich heute (17. Juli) die ‘Goeben〉, jetzt 〈Javus Selim〉, welche in der Bucht von Stenia liegt ... Man ersparte mir mit deutscher Gründlichkeit keinen Raum, keine Treppe; es war keine leichte Aufgabe für jemanden, der durch heftige Ischias auf einem Bein ganz unsicher auftrat, aber es lohnte der Mühe ...» (p. 134)

\section{Die Moukhtar Paschas}

«Im Anschluß an meine Äußerung über sein gutes Befinden fragte mich der Sultan, ob es wahr sei, daß man mir in Berlin gesagt habe, sein Zustand wäre so hoffnungslos, daß an eine Operation nicht mehr gedacht werden könne ... Tatsächlich ... hat mir Mahmud Mukthar, der türkische Botschafter in Berlin, 
etwas ähnliches gesagt, nur konnte ich mir nicht erklären, wie es zur Kenntnis des Sultans gelangt sein konnte ... Als ich nachher den Ärzten gegenüber meiner Verwunderung über die Frage des Sultans Ausdruck gab, sagte man mir, daß diese auf Mahmud Mukthar ziele, dessen Stellung man zu erschüttern suche und dessen Abberufung demnächst in Aussicht stehe. Es bestehe zwischen ihm und Enver eine Gegnerschaft, die darauf beruhe, da $\beta$ Mahmud nicht ganz mit den Anschauungen des jungtürkischen Komitees übereinstimme.» (p.68)

Mahmud Moukhtar Pascha war von 1913 bis 1915 Botschafter in Berlin, doch wurde das Geheimbündnis mit dem Deutschen Reich vom August 1914 ohne sein Wissen von Enver und Said Halim unterzeichnet. Mahmud Moukhtar war mit einer ägyptischen Prinzessin, Tochter des Khediven Ismail (vgl. S. 127), verheiratet. Er trat auch als Schriftsteller in Erscheinung [31]. In einem seiner Bücher gibt er z. B. Rechenschaft als Kommandeur des 3. osmanischen Armeekorps [32].

"Ich erwähnte Hairi ${ }^{16}$ gegenüber meine Absicht, Gazi Moukthar Pascha, den Vater des Botschafters Mahmud Moukthar zu besuchen, teils weil sein Sohn mich darum gebeten hatte, teils weil es mich interessierte, den jetzt 83jährigen Herrn wiederzusehen, der mich vor ca. 11 Jahren in Berlin wegen der Unfähigkeit spontaner Blasenentleerung consultiert hatte. Als ich ihm damals sagte, daß die normale Funktion nur durch Entfernung der Vorsteherdrüse herzustellen sei, fragte er mich, ob durch diese Operation seine Potenz leiden könne. Ich belehrte ihn dahin, daß das im allgemeinen nicht der Fall sei, wohl aber die Zeugungsfähigkeit fortfalle. Ich glaubte, daß dieser Punkt für ihn nicht mehr in Frage kommen könne, hatte mich aber sehr geirrt, denn gerade deshalb lehnte er die Operation ab. Das fand ich für einen Mann jenseits der 70er Jahre damals absurd, wurde aber eines besseren belehrt, als er mir bei meinem jetzigen Besuche seinen 10jährigen Sohn als Produkt der Ablehnung meines Rates vorstellte.» (p. 106)

"In Haidar Pascha ${ }^{7}$ bestiegen wir (am 7. Juli) die beiden mit herrlichen Pferden bespannten Viktorias ${ }^{17}$ des Prinzen (Hilmi) und fuhren zu Gazi Moukthar ... Dieser Besuch wird mir als einer der langweiligsten in Erinnerung bleiben, da der alte Herr nur von seinen Blähungen, seinen Darmstörungen, seiner Blase, seinen Kathetern erzählte - Dinge, die ihn so ganz in Anspruch nahmen, daß daneben nichts Wichtiges in der Welt für ihn zu existieren schien.» (p.109)

Ghazi Ahmed Moukhtar Pascha (1832-1919) verdankte seinen Ehrentitel (Ghazi = der Siegreiche) der Eroberung des Yemen und seinen Erfolgen im Krieg gegen Rußland (1877). Er war in jungen Jahren Hauslehrer des 
Kronprinzen Jussuf Izzeddin (vgl. S.128) gewesen und war später als Vizepräsident des osmanischen Senats maßgeblich an der Absetzung Abdul Hamids II. beteiligt. 1912 war er für kurze Zeit Großwesir.

«Gazi Moukthar war zur Zeit des letzten Balkankrieges Großvezier. Wie man mir sagte, mißt man seiner falschen Beurteilung der Kriegsbereitschaft der türkischen Armee die Schuld zu, daß die Türkei den Krieg gewagt und verloren hat.» (p. 109)

\section{Die Dardanellenschlacht}

Am 9. Juli fuhr Israel «auf Einladung von Suleiman zum Rennen nach Makrikioi ${ }^{18}$... Dort traf ich viele interessante Persönlichkeiten. Zuerst sprach ich Bronsart von Schellendorf, Generalstabschef ...» (p. 118). Friedrich Bronsart von Schellendorf (geb. 1864) war seit Ende 1913 türkischer Generalstabschef, ein Günstling Envers, wurde dann allerdings 1917 durch Hans von Seeckt (1866-1936) abgelöst. In seiner Eigenschaft als Generalstabschef war er die rechte Hand des Kommandanten der 5.türkischen Armee, des Marschalls Liman von Sanders.

Otto Karl Viktor Liman von Sanders (1855-1929) war eigentlich preußischer General der Kavallerie, doch wurden die deutschen Offiziere in türkischen Diensten alle um einen Grad befördert, was bei den türkischen Kameraden nicht eitel Beifall erweckte. Daß Israel den Marschall nicht auch persönlich kennenlernte, hatte seinen guten Grund, denn von Sanders, der künftige Sieger von Gallipoli, war an der Dardanellenfront festgehalten.

Als das Bündnis der Hohen Pforte mit den Zentralmächten perfekt und der Krieg Tatsache geworden war, versuchten die Briten, angefeuert vom Marineminister Winston Churchill (1874-1965), schon zu Beginn des Jahres 1915 einen Durchbruch durch die Dardanellen - und letztendlich Verbindung mit dem verbündeten Rußland - zu erzwingen. Die Meerenge und die Halbinsel Gallipoli wurden für mehrere Monate zum hartumkämpften Kriegsschauplatz, genau in der Zeit also, da Israel in Konstantinopel weilte. Nachdem anfangs 1915 ihr Angriff zur See fehlgeschlagen war, führten die Engländer im April ein Landemanöver aus und trugen den Kampf auf die Halbinsel. Acht Monate wogte die Dardanellenschlacht, bis der Angreifer im Januar 1916 das Feld endgültig räumen mußte und die osmanischen Truppen unter Liman von Sanders siegreich aus dieser Episode des Welt- 
krieges hervorgingen. Im Herbst 1916 erschien in den Zeitungen Konstantinopels eine poetische Verherrlichung der Heldentaten von Gallipoli aus der Feder keines Geringeren als des Sultans Mohammed V. persönlich.

Am 14.Juli sprach Israel v.d.Goltz gegenüber seinen Wunsch aus, «einmal die Front in Gallipoli zu besuchen. Er sagte es seinem Nachbar Enver Pascha und dieser gab mir gern die Erlaubnis, fügte aber hinzu: ‘Da müssen Sie einen großen Regenschirm aufspannen, denn da hagelt es tüchtig>, wobei er natürlich den Geschoßhagel meinte. Leider ist nichts daraus geworden, da ich wegen meiner Ischias nicht zu Pferde steigen konnte.» (p.132)

\section{Die Zeremonie des Mantels}

Am 23. Juli, also einen Monat nach der Operation, «am 8. Jahrestage der Konstitution ${ }^{19}$, bringe ich dem Sultan meine Glückwünsche dar und lasse ihn zum ersten Male aufstehen.» (p. 146) Dieses Ereignis erwartete der Sultan mit großer Ungeduld. "Schon seit einer Woche fragt mich der Sultan mehrmals am Tage, ob er im Stande sein werde, die Zeremonie des Mantels abzuhalten, welche am 15. Tage des Ramasan stattzufinden hat. Zu dieser Zeremonie begibt sich der Sultan nach dem Top Kapu Serail. Dort ist der Mantel des Propheten aufbewahrt, der vom Sultan aus einer Truhe genommen und geküßt wird. Zu beiden Seiten der Truhe sind große Stapel von Musselintüchern mit aufgedruckten Koranversen aufgebaut. Bei der Defiliercour aller hohen Militärs, Beamten und Vornehmen schenkt der Sultan jedem eines der Tücher, welche als Geschenke des Khalifen Glück bringen.» (p.127)

Die Würde des Kalifen, des obersten islamischen Herrschers und Nachfolgers des Propheten, hatte Selim I. (1470-1520) im Jahre 1517 den ägyptischen Abbassiden abgerungen und fortan dem Geschlechte der Osmanen gesichert.

«Das ganze Herz des Sultans hing an der Erfüllung seines Wunsches, da die Teilnahme an der Zeremonie ein äußerst wichtiger politischer Akt ist und sein Fernbleiben zu schlimmen Gerüchten über seinen Gesundheitszustand hätte Veranlassung geben können. Deshalb überlegte ich, wie ich wohl ohne Schädigung seiner Gesundheit es einrichten könnte, ihm die Teilnahme zu gestatten. Zweien dabei notwendigen Anforderungen war er sicher nicht gewachsen. Erstens der mindestens Dreiviertelstunden währenden Wagenfahrt nach Top Kapu Serail, zweitens dem zweistündigen Stehen während der Dauer der Zeremonie. Deshalb schlug ich vor, er möge zu Wasser nach dem alten Serail 
fahren und während der Zeremonie sitzen; beides erwies sich aber als untunlich. Gegen die Wasserfahrt protestierte Enver Pascha wegen der Unterssebootsgefahr auf dem Marmara-Meer und gegen das Sitzen protestierte der Sultan, da keiner seiner Vorfahren jemals anders als stehend die Zeremonie abgehalten hätte ... Da kam mir ein anderer Gedanke. Ich wollte den Scheich ul Islam fragen, ob man nicht die Zeremonie aufeinen andren Tag des Ramasan verlegen könne. Da traf es sich, daß ich Hakki Pascha ${ }^{20}$, dem (späteren) Botschafter in Berlin begegnete und ihm die Frage vorlegte. Er sagte mir mit aller Bestimmtheit, da $\beta$ die Zeremonie ebensogut an jedem anderen Tage des Ramasan stattfinden könne ... und daß darüber der Sultan als Khalif zu befinden, dagegen der Scheich ul Islam nichts zu sagen hätte.» (p. 128)

Sabit Bey, der Obergarderobier (vgl. S.126), löste nun die Aufgabe glänzend, indem er zum Sultan sagte, «Seine Majestät könne doch unmöglich verlangen, da $\beta$ der Professor sein Renommé dadurch aufs Spiel setze, daß er gedrängt würde, seine Erlaubnis zu einem Wagnisse zu geben, bei dem Seiner Majestät etwas passieren könne. Etwas anderes wäre es ja, wenn man die Zeremonie verschieben könne. Leider könne der Sultan das nicht tun, da ihm das Recht dazu fehle. Das ginge doch wohl über seine Macht! Das reizte den Sultan zum Widerspruch, sodaß er zuletzt antwortete: "Sie sind ganz und gar im Irrtum. Über den Tag, an dem die Zeremonie stattfinden soll, habe ich einzig und allein in meiner Eigenschaft als Khalif zu entscheiden. Ich werde daher den 27. Tag (8. August) statt des 15. (27. Juli) bestimmen, und keiner hat mir darin zu widersprechen.» (p. 129)

Leider hat infolge dieser Verschiebung Israel der Zeremonie des Mantels nicht mehr selbst beiwohnen können. Er ist am 30 . Juli ${ }^{21}$ wieder nach der Heimat abgereist.

\section{Abschied vom Sultan und dessen weiteres Schicksal}

28. Juli: "Als ich zum Sultan ging, um ihm zu danken, wurde mir der Osmanié Orden I. Klasse angelegt. So dekoriert mußte ich auf Wunsch des Sultans nach Hause gehen, damit die Haremsdamen mich von ihren vergitterten Fenstern aus beobachten könnten. Alles gratulierte. Die Auszeichnung ist die höchste, welche der Sultan zu vergeben hat. Vor einigen Tagen hat sie auch Liman von Sanders ${ }^{22}$ erhalten.» (p. 153)

29. Juli: «Ich verabschiedete mich heute vom Sultan, nicht ohne eine gewisse Bewegtheit, denn ich hatte ihn wahrhaftig lieb gewonnen. 
Er stand von seinem Sessel auf und dankte mir mit herzlichen Worten, auf die ich nur wenig sagen konnte, weil mich die Rührung übermannte. Es war ein eigenes Gefühl, mit diesem Abschied eine Episode beendet zu sehen, die für die ganze Welt von Bedeutung war. Wäre es mir nicht gelungen, den Sultan seiner schweren Krankheit zu entreißen, und wäre ein Thronwechsel eingetreten, so hätte man keine Sicherheit für den Fortbestand des deutsch-türkischen Bündnisses haben können. Ich empfand es in diesem Augenblick als ein erhebendes Gefühl, uns und der verbündeten Türkei einen großen Dienst erwiesen und dem deutschen Namen Ehre gemacht zu haben ${ }^{23}$.»

«Wahrscheinlich infolge des hohen Alters des Patienten war aber die Besserung nicht von langer Dauer, und der Sultan litt wieder unter häufigen und sehr schmerzhaften Krampf- und Kolikanfällen: So z. B. befiel ihn ein solcher Krampfanfall» (im Mai 1918) «während der großen Soirée zu Ehren des österreichisch-ungarischen Kaiserpaares, so daß er das Fest verlassen und in seine Wohnung überführt werden mußte. Damals erholte er sich rasch, konnte schon am nächsten Tage abends dem Kaiserpaar das Geleite auf den Bahnhof geben und sich dort von ihm verabschieden. Am 1.Juli hatte er aber einen neuerlichen, besonders schweren Anfall, welchem er nach zweitägigem Leiden erlag. ${ }^{24}$

Es erscheint indessen zweifelhaft, ob die hier geschilderten Anfälle ausschließlich auf urologischen Beschwerden beruhten. Letztere sollen nämlich durch Israels Intervention erfolgreich und endgültig behoben worden sein. Doch war die durch jene Beschwerden sowie durch ungesunde Lebensweise bedingte allgemeine Schwächung nicht mehr rückgängig zu machen. In seinen letzten Lebensmonaten bedurfte Mohammed V. deshalb nicht mehr des Beistandes eines Urologen, sondern vielmehr eines Internisten, dies in der Person des Berliner Professors Friedrich Kraus (1858-1936; [3]) [24].

\section{Rückreise mit Komplikationen}

Neben vielen Ehrungen und Geschenken, die Israel zuteil wurden, waren seine letzten Tage in Konstantinopel durch seltsame Umtriebe überschattet. «Mme. de Villebois, die Frau des holländischen Gesandten, ließ sich mir vorstellen und wiederholte die von unserem Botschafter ausgesprochene Bitte zur Konsultation bei einer hochstehenden Persönlichkeit nach Bukarest zu fahren (p.91) ... Ich antwortete ihr, daß ich kommen würde, wenn der Auftraggeber seine Anonymität lüftete.» (p.118) 
Am 29. Juli «zeigte mir der Botschaftsrat von Neurath einen Brief des rumänischen Gesandten, in dem mir amtlich unter Diskretion mitgeteilt wurde, daß der König von Rumänien ${ }^{25}$ der Patient sei.» (p. 155)

«Bei Ankunft auf dem Bahnhof in Bukarest sah ich mich vergeblich nach einem Abgesandten des Hofes um. Niemand erwartete mich. Nun fuhr ich nach dem Hotel, welches ich dem Fürsten Hohenlohe ${ }^{10}$ als meine Adresse ... genannt hatte. Aber auch hier war niemand, der mich erwartete; niemand hatte nach mir gefragt, noch war ein Brief oder eine Nachricht für mich eingelaufen.

Nachdem ich enttäuscht und ärgerlich 2 Stunden im Hotel gewartet hatte..., ging ich selbst zur Gesandtschaft, um zu hören, ob einer der Attachés über meine Angelegenheit informiert sei. Ich traf» einen einzigen "Herrn und dieser wußte von nichts ... Darauf schrieb ich umgehend dem Gesandten: Da ich aus seinem Brief ersähe, daß der König gar nichts von meinem Kommen wisse, ich also annehmen müsse, daß meine Berufung von einer mir unbekannten, nicht autorisierten Persönlichkeit erfolgt sei, so müsse ich darauf verzichten, dem König Dienste zu leisten, um welche er mich nicht gebeten habe.

Übrigens glaube ich annehmen zu dürfen, da $\beta$ entweder Carmen Sylva ${ }^{26}$ oder die Königin mich hierher gerufen aber nicht gewagt haben, es dem Könige zu sagen, weil er sich stets energisch gegen jede Untersuchung gewehrt hat.

Abgesehen von dem Ärger über die Taktlosigkeit des rumänischen Hofes, hatte ich noch den Nachteil davon, einen Tag in Bukarest und meinen Schlafwagen nach Budapest zu verlieren.» (p. 159-161)

«Am 3. August morgens kam ich in Berlin an, zwar körperlich stark mitgenommen durch eine heftige Ischias und einen ruhrartigen Darmkatarrh, aber gehoben durch das Bewußtsein, Außergewöhnliches erlebt und eine ungewöhnlich verantwortliche Aufgabe glücklich gelöst zu haben.» (p. 162)

\section{Anmerkungen}

${ }^{1}$ Herrn und Frau Prof. Nissen danke ich ergebenst für den gründlichen Einblick in das Original.

2 Seitenzahlen (S. ...) der vorliegenden Abhandlung.

${ }^{3}$ Nach jedem Zitat: Seitenzahl (p...) des Originals, welches in unveränderter Rechtschreibung und Interpunktion wiedergegeben ist. Dies gilt z. B. auch für den türkischen Namen «Moukhtar»/Mukhtar» (vgl. [31], [32]), den Israel stets anders transliteriert («Moukthar»).

${ }^{4}$ Die türkische Provinz Albanien machte sich 1912 im ersten Balkankrieg durch Unabhängigkeitserklärung selbständig.

5 Ernst von Leyden (1832-1910). 
${ }^{6}$ Gemeint ist der Balkankrieg.

${ }^{7}$ Vorort von Skutari, also auf der kleinasiatischen Gegenseite von Konstantinopel.

${ }^{8}$ Vgl. S. 128.

${ }^{9}$ Karl Veit Franz (1870-1926), Ordinarius für Gynäkologie in Jena (1904-1910) und Berlin (1910-1926).

${ }^{10}$ Fürst Ernst, ein Sohn des kaiserlichen Statthalters in Elsaß-Lothringen, Großneffe der englischen Königin Victoria und Schwager des Königs Ferdinand von Rumänien, war während des Weltkrieges Generaldelegierter für die freiwillige Krankenpflege an der Ostfront (vgl. auch S. 145).

${ }^{11}$ Gehörte zum Stabe von Suleiman Noueman Pascha [23].

12 Nachdem er früher den Harnabflußweg an seinem tiefsten Punkte, d.h. durch das Perineum zu drainieren pflegte [33], ging Israel später dazu über, im Falle der Sectio alta durch die Bauchwand direkt nach außen zu drainieren, also ohne vollständigen, primären Blasenverschluß [34].

${ }^{13}$ Palast am Bosporus, im nordöstlichen Teil Konstantinopels. Der Name bedeutet wörtlich «wohlgefüllter Garten». Dieser war zu Zeiten Suleimans II. (Sultan 1687-1691) durch den Einsatz von 16000 christlichen Sklaven dem Meere abgerungen worden, durch Landaufschüttung also [35].

14 Vgl. die Stammtafel S. 123.

${ }^{15}$ Bartolomeo Colleoni (1400-1475), Söldnerführer in neapolitanischen, mailändischen und venezianischen Diensten; Reiterstandbild von Verrochio in Venedig.

${ }^{16}$ Leibarzt Hairi Pascha (vgl. S. 125).

${ }_{17}$ Aus England stammendes, nach der Königin Victoria benanntes Modell einer vierrädrigen Kutsche ohne Türen. Der Passagiersitz ist durch ein zusammenlegbares Verdeck geschützt. Im allgemeinen Sprachgebrauch der Zeit wurde die Victoria vielfach mit dem zweirädrigen Cabriolet verwechselt.

${ }^{18}$ Vorort, wenige Kilometer von Konstantinopel, am Maramarameer; mit Munitionsfabrik.

${ }^{19}$ Genau am 24. Juli 1908: Wiedereinsetzung der von Abdul Hamid II. aufgehobenen Verfassung vom 23. Sept. 1876.

${ }^{20}$ Ibrahim Hakki Pascha, 1910-11 Großwesir, 1915 Botschafter in Berlin als Nachfolger von Mahmud Moukhtar Pascha (vgl. S.139), Mitunterzeichner des Friedens zwischen den Mittelmächten und Rußland am 3. März 1918 in Brest-Litowsk.

${ }^{21}$ Nach islamischer Zeitrechnung dauerte Israels Aufenthalt in Konstantinopel vom 4. Schaban (17. Juni) bis zum 18. Ramasan (30. Juli) des Jahres 1333, welches vom 19. Nov. 1914 bis zum 8. Nov. 1915 dauerte.

22 Vgl. S. 141 .

${ }^{23}$ Im Original: «heben».

${ }^{24}$ Aus Pomiankowski [21] p. 354.

${ }^{25}$ Ferdinand I. von Hohenzollern-Sigmaringen (1865-1927, König seit 1914).

${ }^{26}$ Dichterinnen-Pseudonym der Königinmutter Elisabeth Pauline Ottilie Louise, geb. Fürstin von Wied (1843-1916). 


\section{Zitierte Literatur}

[1] Lehmann, Hartmut: James Israel (1848-1926), Biobibliographie eines Berliner Chirurgen und Urologen. Diss. med. dent. Freie Univ. Berlin 1977

[2] Rosenstein, Paul: James Israel. Med. Klin. 22: 635-637 (1926)

[3] Kraus, Friedrich, in: Trauerfeier für James Israel. Z. Urol. 20: 717-720 (1926)

[4] Bloch, Peter, James Israel \& Fritz Schultze-Seemann: James Israel 1848-1926. Herausg. Rud. Winau. Wiesbaden: Franz Steiner, 1983

[5] Alderson, Anthony Dolphin: The Structure of the Ottoman Dynasty. Oxford: Clarendon Press, 1956

[6] Anon.: Traços biograficos do Professor Rocha Lima. Arquivos Inst. Bio. Sao Paulo 11: XVII-XXVI (1940)

[7] Niedner, Otto: Die Kriegsepidemien des 19.Jahrhunderts und ihre Bekämpfung. Bibliothek v. Coler, Bd. 17; Berlin: Hirschwald 1903

[8] Sackmann, Werner: Fleckfieber und Fleckfieberforschung zur Zeit des Ersten Weltkrieges. Gesnerus 37: 113-132 (1980)

[9] His, Wilhelm: Die Front der Ärzte. Bielefeld-Leipzig: Velhagen \& Klasing, 1931

[10] Jahresber. ges. Med.41: I: 468 (1906)

[11] Moulonguet, André: Le Professeur N. Taptas. Ann. otolaryngol.72: 745-746 (1955)

[12] Portmann, G.: Le Professeur N. Taptas. Rev. laryngol. Bordeaux 76: 947 (1955)

[13] Müller, H. Aurel: Selmar Aschheim zum 80. Geburtstag. Neue Z. f. ärztl. Fortbildg. N.F. 1 (47): 518 (1958)

[14] Courrier, Robert: Allocution (et réponse). Ann. Endocrinol. 15: 243-252 (1954)

[15] R.: Selmar Aschheim (1878-1965). Méd. Hyg. 689: 558 (1965)

[16] Aschheim, Selmar: Weitere Untersuchungen über Hormone und Schwangerschaft. Arch. Gynäkol. 132: 179-183 (1927)

[17] Aschheim, Selmar, \& Bernhard Zondek: Schwangerschaftsdiagnose aus dem Harn (Durch Hormonnachweis). Klin. Wochenschr. 7: 8-9 (1928)

[18] Aschheim, Selmar, \& Bernhard Zondek: Die Schwangerschaftsdiagnose aus dem Harn durch Nachweis des Hypophysenvorderlappenhormons. Klin. Wochenschr. 7: 1404-1411, 1453-1457 (1928)

[19] Ziehen, Theodor: Diskussion Psychiatr. Verein Berlin (17.Dez. 1910). Neurol. Zentralbl. 30: 109-110 (1911)

[20] Oppenheim, Hermann: Über eine eigenartige Krampfkrankheit des kindlichen und jugendlichen Alters (Dysbasia lordotica progressiva, Dystonia musculorum deformans). Neurol. Zentralbl. 30: 1090-1107 (1911)

[21] von Pomiankowski, Joseph: Der Zusammenbruch des ottomanischen Reiches. ZürichLeipzig-Wien: Amalthea Verlag, 1928

[22] von der Goltz, Colmar: Denkwürdigkeiten, 2. Aufl. Berlin: Mittler, 1932

[23] Bentmann, Eugen: Kriegsärztliche Erfahrungen in Anatolien. Arch. Schiffs- \& Tropenhyg. 27: Beiheft Nr.1 (1923)

[24] Persönl. Mitteilung P. Bloch. New York

[25] Lichtheim, Richard: Die Geschichte des deutschen Zionismus. Jerusalem: Rubin Mass, 1954 
[26] Morgenthau, Henry: Ambassador Morgenthau's Story. Garden City N. Y.: Doubleday, Page \& Co., 1918

[27] Morgenthau, Henry: I was sent to Athens. Garden City N. Y.: Doubleday, Goran \& Co., 1929

[28] von Giesl, Wladimir: Zwei Jahrzehnte im nahen Orient. Berlin: Verlag f.Kultur \& Politik, 1927

[29] Buchholtz, Arend: Ernst von Bergmann. Leipzig: Vogel, 1911

[30] Mühlmann, Carl: Das deutsch-türkische Waffenbündnis im Weltkriege. Leipzig: Koehler \& Amelang, 1940

[31] Moukhtar Pacha, (Mahmud): La Turquie, l'Allemagne et l'Europe depuis le traité de Berlin jusqu'à la guerre mondiale. Nancy-Paris: Berger-Levrault, 1924

[32] Mahmud Mukhtar Pascha: Meine Führung im Balkankriege 1912. Berlin: Mittler, 1913

[33] Israel, James (Diskussionsvotum). Verh. dtsch. Ges. Chir. 34: 210-211 (1905)

[34] Israel, James (Diskussionsvotum). Verh. dtsch. Ges. Chir. 36: 186-188 (1907)

[35] Frank, Gerd: Die Herrscher der Osmanen. Wien-Düsseldorf: Econ-Verlag, 1977

\section{Summary}

In 1915, the German surgeon and urologist James Israel stayed for six weeks in Constantinople (Istanbul), the capital of the Ottoman Empire, which was an ally of Germany in World War I. Israel was the guest of Sultan Mohammed V.; he cured the sovereign of serious urolithiasis by sectio alta.

Israel wrote down his impressions, the acquaintancies he made among the Turkish upper classes and European diplomats and military men, and many other experiences in an informative and entertaining diary. This document is only reproduced in part; but its merits with respect to the history of civilization and of medicine are none the less worthy of note.

Dr. med. vet. Werner Sackmann

Sieglinweg 10

CH-4.125 Riehen 